Original article

\title{
Understanding of biostatistics among the homeopathic fresh graduates and post-graduate trainees in West Bengal, India
}

\author{
Subhranil Saha ${ }^{1}$, Munmun Koley ${ }^{1}$, Ramkumar Mondal ${ }^{2}$, Monojit Kundu³,
} Aloke Ghosh ${ }^{4}$, Shubhamoy Ghosh ${ }^{2}$, Sangita Saha ${ }^{5}$, Subhasish Ganguly ${ }^{6}$

(1) Central Council of Homeopathy, Govt. of India

(2) Mahesh Bhattacharyya Homeopathic Medical College and Hospital, India

(3) Council of Homeopathic Medicine, West Bengal, India

(4) Midnapore Homeopathic Medical College and Hospital, West Bengal, India

(5) Calcutta Homeopathic Medical College and Hospital, West Bengal, India

(6) D N De Homeopathic Medical College and Hospital, West Bengal, India

\begin{abstract}
Background: A basic understanding of biostatistics is essential, both for designing quality research and evaluating medical literature. We evaluated the understanding of biostatistics and interpretation of research results among homeopathic fresh graduates' (House Staffs; HSs) and postgraduate trainees' (PGTs) in West Bengal, India. Methods: A cross-sectional survey of homeopathic HSs and PGTs in the four government homeopathic schools in West Bengal, India, using a pre-tested, valid and reliable biostatistics multiple choice knowledge, confidence and attitude test questionnaire. Results: Internal consistency of the used questionnaires was acceptable (Cronbach's $\alpha=0.611$ - 0.672). Response rate was only 55.6\%. Research journal reading habit was seriously lacking. No one had ever taken any research courses or possessed any advanced degrees or diplomas. The overall mean\% correct on statistical knowledge was very poor, $1.0 \%(95 \%$ CI $0.1-1.9 \%)$ vs. $10.0 \%$ (95\% CI $8.6-11.6 \%)$ for HSs and PGTs $(P<0.0001)$. Comparatively, higher knowledge scores were found in respondents from Mahesh Bhattacharyya Homeopathic Medical College and Hospital $(P=0.003)$. No one could interpret an unadjusted odds ratio, Kaplan-Meier analysis results, and determine strength of evidence for risk factors. Percentages of correct answers for all other knowledge-based questions ranged between only 2.7 9.5\%. Respondents' self-assessed confidence in ability to understand biostatistics ranged between 41 - 60\%. Positive attitude towards biostatistics was elicited in $16-63 \%$ respondents. Conclusions: The respondents seriously lacked knowledge in biostatistics needed to interpret research results. Training programs needs to undergo massive and immediate transformation to include more effective biostatistics training in curricula to encourage meaningful research.
\end{abstract}

Keywords: Biostatistics, trainees, homeopathy. 


\section{Introduction}

Prioritizing research in medical curriculum has been emphasized to develop critical analytical skills and thinking, independent writing, future clinical practice, enhanced employability, and improved research productivity [1]. Research evidence is a pre-requisite in ensuring provision of the best possible care to patients in the most effective and efficient manner [2]. Students and practitioners need continually updating them to keep abreast of relevant exponentially expanding knowledge of research. But unfortunately, a serious decline has been observed in medical graduates choosing research as careers in the last two decades [3-5], and 'clinician-scientists' have already been identified as an 'endangered species' [6], a 'vulnerable population' [7].

In health care sciences, understanding biostatistics may have important implications in modulating clinical practice as it possesses a large effect on evidence-based diagnostic and treatment applications. Though homeopathy is claimed to be safe and effective, there is an ethical mandate to evaluate the same, and also how specifically it works, thereby improving confidence and quality of care in clinical practice, developing scientific evidence-base and provide information for making decision to the politicians and other stakeholders. Thus a clear understanding of the basics of biostatistics and biomedical research becomes a prerequisite to critically evaluate various research studies in the fields concerned. Similarly, in academics, sufficient knowledge of epidemiological principles is required to successfully conduct a study and correctly analyse data derived from clinical investigations [8]. Still the scenario remains dismal in homeopathy. Despite far reaching consequences, homeopathic HSs and PGTs knowledge and attitude towards research and biostatistics has barely been investigated to date. A recent study unveiled that their knowledge about homeopathic research remained seriously compromised [9]. Stipendiary post-graduation courses in homeopathy of 3 years duration were initiated in two of the four government homeopathic schools in West Bengal in 2004 in three homeopathic specialties - Repertory, Materia Medica, and Organon of Medicine. Since then until December 2013, a total of 352 candidates completed post-graduation successfully. In spite of provision of formal training of basic research methodologies and biostatistics in the curriculum, it received minimal attention. Consequently, contribution to quality homeopathic research by the homeopathic PGTs remained miniscule. Most of the research produced was through required dissertations that were mandatory requirements for successful completion of their training, seldom published in any peer-reviewed research journal. The fact is substantiated by that, from 2004 to 2013, only a single MEDLINE-indexed research paper was published that granted authorship to the homeopathic undergraduate students [10], a single peer-reviewed paper by the house staff (HS) [11], but not even a single one by the PGTs in West Bengal. In this project, the authors intend to evaluate their knowledge of and attitude towards biostatistics and formulate corrective recommendations.

\section{Methods}

Setting and design: A cross-sectional survey was carried out during January, 2014 in the four Government homeopathic medical colleges of West Bengal, India, namely Midnapore Homeopathic Medical College and Hospital (MHMCH), D N De Homeopathic Medical College and Hospital (DNDHMCH), Mahesh Bhattacharyya Homeopathic Medical College and Hospital (MBHMCH), and Calcutta Homeopathic Medical College and Hospital (CHMCH). Permission was taken from the institutional ethics committees of the respective institutions prior conduct of the study. Written consent was obtained from each participant after providing a description of the survey's purpose in participants' information sheet.

Participants: Out of total 97 HSs and 36 PGTs working in the four homeopathic degree granting colleges under approval of West Bengal University of Health Sciences (WBUHS), Government of West Bengal and under affiliation to Central Council of Homeopathy, Government of India, total 74 (40 HSs and 34 PGTs; 54.1 and $45.9 \%$ respectively) participated and returned the questionnaire. 
Sample size: Considering margin of error as $5 \%$, confidence level $95 \%$, and response distribution estimated to be $50 \%$ as prevalence of good knowledge and attitude, and population size of 133 , target sample size became 99 . However, as we obtained only 74 responses, the confidence level was reduced to $80 \%$.

Questionnaire and data analysis plan: No universally accepted standardized questionnaire was available to evaluate homeopathic HSs' and PGTs' existing level of knowledge of biostatistics. With prior permission, we used a pre-tested, previously validated, internally consistent (Cronbach's a $=0.81$ ), structured, selfadministered questionnaire, developed and used by Windish D, et al, 2007 [12] to test medicine residents' understanding of biostatistics. The directions to fill up the questionnaire were explained verbally to all the respondents in detail by the research assistants. The questionnaire consisted of four sections.

The first section sought data on the socio-demographic profile of the respondents regarding their gender, age, institution, possession of advanced degree(s) or diploma(s), years since homeopathic graduation, current level of training, residency or postgraduate training program type, previous training in biostatistics, epidemiology, and/or evidence-based medicine (EBM), and whether read medical, homeopathic or complementary and alternative medicine (CAM) research journals regularly.

The second section comprised of five questions exploring the respondents' attitude towards biostatistics using a 5-point Likert agreement scale. Section C, consisting of 4 questions, was aimed at evaluating the confidence of the respondents in the current level of ability in assessing, identifying, and interpreting statistical terms. Section D consisted of 16 questions provided with multiple probable answers focusing on the respondents' knowledge of biostatistics.

To evaluate the feasibility of application of the questionnaire, a pilot testing was conducted on twelve participants involving three from each institution prior the survey. Instructions on the questionnaire promised anonymity. No participant identifiable information was required to ensure protection of privacy. Also the filled in questionnaires were concealed by putting those inside opaque envelops which were sealed at the survey site by the respondents themselves. All these were collected by the research assistants and were sent for data analysis. All the responses were individually extracted in a specially designed excel sheets and subjected to statistical analysis using computational websites.

Statistical analysis plan: Descriptive statistics were presented in the form of absolute numbers and percentages. Bivariate analyses using one-way ANOVA and independent $t$ test were performed to identify putative associations of variables that might be associated with knowledge scores.

Forward stepwise multiple linear regressions were subsequently used to identify which demographic factors were independently associated with biostatistics knowledge scores. Missing values were counted as incorrect responses. To adjust for multiple pair-wise comparisons, a 2 -sided level of statistical significance was set at $P$ $<0.01$ using a Bonferroni correction.

\section{Results}

The item-corrected total correlations (Pearson's $r$ ) for the used questionnaires are shown in table 1 . Total 16 values are equal to or above the cut-off point of $0.3(0.30-0.70), 10$ values are less than $0.3(0.14-0.29)$, and the rest three values were not applicable because no one could answer these questions correctly. Overall, all the questions contributed moderately to the three subsets of questionnaire. The used attitude, confidence, and knowledge-based questionnaire appeared to have acceptable internal consistency; Cronbach's alpha 0.611, 0.672 , and 0.647 respectively. 
Table 1: Internal consistency of the used questionnaire

\begin{tabular}{|c|c|c|}
\hline Questions & Pearson's $r(95 \%$ CI $)$ & Cronbach's alpha \\
\hline $\begin{array}{cc}\text { Attitude questionnaire } \\
\text { - } & \mathrm{Q} 1 \\
\text { - } & \mathrm{Q} 2 \\
\text { - } & \mathrm{Q} 3 \\
\text { - } & \mathrm{Q} 4 \\
\text { - } & \mathrm{Q} 5\end{array}$ & $\begin{array}{l}0.60(0.43-0.73) \\
0.34(0.12-0.53) \\
0.46(0.26-0.62) \\
0.44(0.24-0.61) \\
0.45(0.25-0.62)\end{array}$ & 0.611 \\
\hline $\begin{array}{c}\text { Confidence questionnaire } \\
\text { - } \mathrm{Q} 1 \\
\text { - } \mathrm{Q} 2 \\
\text { - } \mathrm{Q} 3 \\
\text { - } \mathrm{Q} 4\end{array}$ & $\begin{array}{l}0.32(0.09-0.51) \\
0.70(0.56-0.80) \\
0.56(0.38-0.69) \\
0.60(0.43-0.73)\end{array}$ & 0.672 \\
\hline 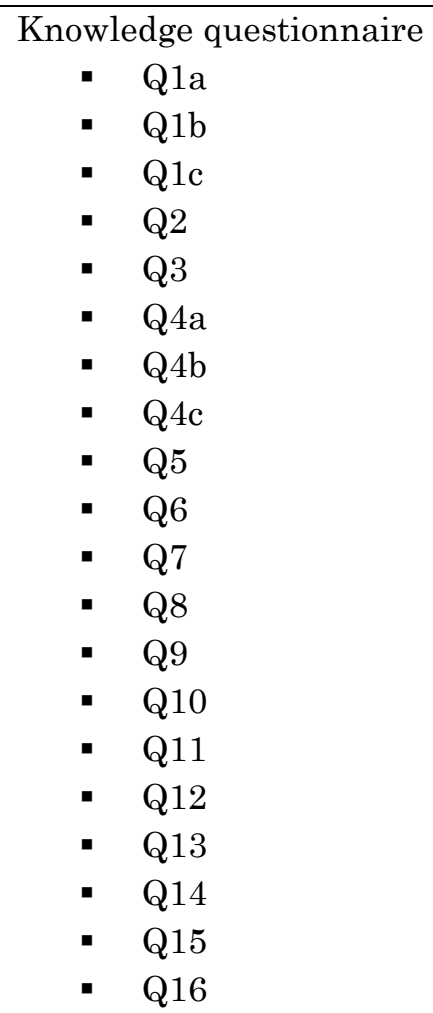 & $\begin{array}{l}0.30(0.08-0.49) \\
0.28(0.06-0.48) \\
0.29(0.07-0.49) \\
0.41(0.20-0.58) \\
0.22(-0.01-0.43) \\
0.39(0.18-0.57) \\
0.32(0.09-0.51) \\
0.25(0.02-0.45) \\
0.25(0.02-0.45) \\
0.29(0.07-0.49) \\
0.29(0.07-0.49) \\
0.30(0.08-0.49) \\
0.30(0.08-0.49) \\
0.30(0.08-0.49) \\
0.21(-0.02-0.42) \\
\text { NA } \\
0.29(0.07-0.49) \\
0.14(-0.09-0.36) \\
\text { NA } \\
\text { NA }\end{array}$ & 0.647 \\
\hline
\end{tabular}

Pearson's $r$ cut-off point taken as $0.3 ; 0.6 \leq$ Cronbach's alpha $<0.7$ considered as acceptable.

Out of 133,74 returned the questionnaire with a response rate of only $55.6 \%$. Majority were men (47, $63.5 \%)$. Maximum responses were obtained from MBHMCH (28, 37.8\%). Among the respondents, 40 (54.1\%) were HSs, and rest 34 (45.9\%) were PGTs. No one possessed any advanced degrees or diplomas, or ever had not undergone any course in epidemiology, biostatistics and/or evidence-based medicine. Research journal reading habit, either mainstream or homeopathic, remained seriously compromised, and in fact, only a single respondent reported of reading homeopathic research journals. Further respondents' characteristics are detailed in table 2 . 
Table 2: Characteristics of the respondents $(\mathrm{N}=74)$

\begin{tabular}{|c|c|}
\hline Characteristic & Number (\%) \\
\hline $\begin{aligned} \text { Gender } & \\
\text { - } & \text { Men } \\
\text { - } & \text { Women }\end{aligned}$ & $\begin{array}{l}47(63.5) \\
27(36.5)\end{array}$ \\
\hline $\begin{array}{l}\text { Age range, years } \\
\qquad \begin{array}{r}26-30 \\
\text { - } \quad 31-35\end{array}\end{array}$ & $\begin{array}{l}38(51.4) \\
36(48.6)\end{array}$ \\
\hline $\begin{aligned} \text { Institutions } \\
\text { - } \mathrm{MHMCH} \\
\text { - } \mathrm{DNDHMCH} \\
\text { - } \mathrm{MBHMCH} \\
\text { - } \mathrm{CHMCH}\end{aligned}$ & $\begin{array}{l}12(16.2) \\
24(32.4) \\
28(37.8) \\
10(13.5)\end{array}$ \\
\hline $\begin{array}{l}\text { Other advanced degree(s)/diploma(s) } \\
\text { - None }\end{array}$ & $74(100)$ \\
\hline $\begin{array}{c}\text { Years since homeopathy graduation } \\
\text { - Less than one } \\
\text { - } \text { One or above }\end{array}$ & $\begin{array}{l}35(47.3) \\
39(52.7)\end{array}$ \\
\hline $\begin{aligned} & \text { Current level of training } \\
& \text { - } \text { House staff } \\
& \text { - } \text { Postgraduate trainee }\end{aligned}$ & $\begin{array}{l}40(54.1) \\
34(45.9)\end{array}$ \\
\hline Ever taken a course in epidemiology, biostatistics and/or EBM & $0(0)$ \\
\hline Regularly reads medical journals & $0(0)$ \\
\hline Regularly reads homeopathy or CAM research journals & $1(1.4)$ \\
\hline
\end{tabular}

EBM = Evidence-based Medicine CAM = Complementary and Alternative Medicine

Table 3 describes respondents' attitude towards need of learning biostatistics that was moderate, between $21.6-85.1 \% .47$ (63.5\%) had mistrust in statistics as they considered it was easy to lie with.

Table 3: Attitude towards biostatistics $(\mathrm{N}=74)$

\begin{tabular}{|rl|c|}
\hline Items & & Number (\%) \\
\hline - & Given the chance, would like to learn more about biostatistics & $16(21.6)$ \\
\hline - & Feel need to understand the statistical terms encountered in journal articles & $34(45.9)$ \\
\hline - & Mistrust in statistics as it is easy to lie with & $47(63.5)$ \\
\hline - & Feel need to use statistical information often in making decisions in medical care & $63(85.1)$ \\
\hline - & $\begin{array}{l}\text { Feels necessity to know something about statistics to be an intelligent reader of } \\
\text { the literature }\end{array}$ & $56(75.7)$ \\
\hline
\end{tabular}


Table 4 reflects respondents' self-assessed confidence in their current level of ability of understanding biostatistical terms including $P$ values, research methods, research question, and study power. $55.4-81.1 \%$ felt confident in understanding these terms.

Table 4: Confidence in current level of ability of understanding biostatistics $(\mathrm{N}=74)$

\begin{tabular}{|c|c|}
\hline Items & Number (\%) \\
\hline - Interpreting the $P$ value for a given result & $41(55.4)$ \\
\hline - Interpreting the results of a statistical method used in research & $43(58.1)$ \\
\hline $\begin{array}{l}\text { - Assessing if the correct statistical procedure was used to answer a research } \\
\text { question }\end{array}$ & $60(81.1)$ \\
\hline - Identifying the factors that influence a study's power & $53(71.6)$ \\
\hline
\end{tabular}

However, table 5 depicts an alarming scenario. Only $2.7-9.1 \%$ participants could provide correct answers to the knowledge questions. No one could interpret an unadjusted odds ratio, Kaplan-Meier analysis results, and determine strength of evidence for risk factors. While $55.4 \%$ participants felt confident in interpreting $P$ values correctly, only $8.1 \%$ could provide the correct answer. While $71.6 \%$ felt confident in identifying the factors that influence a study's power, only $5.4 \%$ could identify so.

Table 5: Percentages of correct answers for the knowledge-based questions ( $\mathrm{N}=74)$

\begin{tabular}{|l|l|l|}
\hline Question No. & Objective & Correct \% (95\% CI) \\
\hline $1 \mathrm{a}$ & Identify continuous variable & $5.4(1.8-14.0)$ \\
\hline $1 \mathrm{~b}$ & Identify ordinal variable & $2.7(0.5-10.3)$ \\
\hline $1 \mathrm{c}$ & Identify nominal variable & $4.1(1.1-12.2)$ \\
\hline 2 & Recognize a case-control study & $6.8(2.5-15.7)$ \\
\hline 3 & Recognize purpose of double-blind studies & $6.8(2.5-15.7)$ \\
\hline $4 \mathrm{a}$ & Identify ANOVA & $9.5(4.2-19.1)$ \\
\hline $4 \mathrm{~b}$ & Identify $\mathrm{X}^{2}$ analysis & $6.8(2.5-15.7)$ \\
\hline $4 \mathrm{c}$ & Identify $t$ test & $8.1(3.3-17.4)$ \\
\hline 5 & Recognize definition of bias & $8.1(3.3-17.4)$ \\
\hline 6 & Interpret the meaning of $P$ value & $8.1(3.3-17.4)$ \\
\hline 7 & Identify Cox proportional hazard regression & $8.1(3.3-17.4)$ \\
\hline 8 & Interpret standard deviation & $5.4(1.8-14.0)$ \\
\hline 9 & Interpret $95 \%$ CI and statistical significance & $5.4(1.8-14.0)$ \\
\hline 10 & Recognize power, sample size, and significance-level relationship & $5.4(1.8-14.0)$ \\
\hline 11 & Determine which test has more specificity & $2.7(0.5-10.3)$ \\
\hline 12 & Interpret an unadjusted odds ratio & $0(0-6.2)$ \\
\hline 13 & Interpret odds ratio in multivariate regression analysis & $8.1(3.3-17.4)$ \\
\hline 14 & Interpret relative risk & $2.7(0.5-10.3)$ \\
\hline 15 & Determine strength of evidence for risk factors & $0(0-6.2)$ \\
\hline 16 & Interpret Kaplan-Meier analysis results & $0(0-6.2)$ \\
\hline & Abbreviatons: ANOVA - anaysis of variance; - confden & \\
\hline
\end{tabular}

Abbreviations: ANOVA - analysis of variance; CI - confidence interval 
Table 6 represents the respondents' characteristics influence on their knowledge scores. Though bivariate analysis identified institution and level of training as influencing factors, the multiple linear regressions could not establish the influence of any factors $(P=0.071-1.432)$. Participants from MBHMCH had slightly higher mean score percentage $(7.7 ; 95 \%$ CI 5.1 to $10.3 ; P=0.003)$ than others. The PGTs have comparatively higher mean score percentage $(10.0 ; 95 \%$ CI 8.6 to 11.6; $P<0.0001)$ in comparison with the HSs. As research journal reading habit was almost absent in the sample studied, and the respondents did not have any research trainings or additional qualifications, influence of these factors could not be evaluated in this study.

Table 6: Knowledge scores by respondents' characteristics (a) $(\mathrm{N}=74)$

\begin{tabular}{|c|c|c|c|c|}
\hline \multirow[b]{2}{*}{ Characteristic } & \multicolumn{2}{|l|}{ Bivariate analysis } & \multicolumn{2}{|l|}{ Multiple linear regression } \\
\hline & Mean score \% (95\% CI) & $P$ value & Score difference \% (d) $(95 \%$ CI) & $P$ value \\
\hline \multicolumn{5}{|l|}{ Gender } \\
\hline - $\quad$ Men & $5.9(4.4$ to 7.8$)$ & \multirow{2}{*}{$0.169^{(b)}$} & 1 [Reference] & \multirow{2}{*}{0.071} \\
\hline - Women & $4.1(3.3$ to 6.5$)$ & & $0.4(-0.1$ to 0.9$)$ & \\
\hline \multicolumn{5}{|l|}{ Age range, years } \\
\hline - $26-30$ & $6.0(3.9$ to 8.1$)$ & \multirow{2}{*}{$0.268^{(\mathrm{b})}$} & 1 [Reference] & \multirow{2}{*}{0.385} \\
\hline - $31-35$ & $4.5(3.5$ to 6.5$)$ & & $0.3(-0.2$ to 0.8$)$ & \\
\hline \multicolumn{5}{|l|}{ Institutions } \\
\hline - $\mathrm{MHMCH}$ & $1.7(-0.7$ to 4.1$)$ & \multirow{4}{*}{$0.003^{(\mathrm{c})}$} & 1 [Reference] & \multirow{4}{*}{0.187} \\
\hline - DNDHMCH & $5.4(3.5$ to 7.3$)$ & & $-0.8(-1.4$ to -0.2$)$ & \\
\hline - $\mathrm{MBHMCH}$ & $7.7(5.1$ to 10.3$)$ & & $-1.2(-2.0$ to -0.4$)$ & \\
\hline - $\mathrm{CHMCH}$ & $2.0(-0.4$ to 4.4$)$ & & $-0.1(-0.7$ to 0.5$)$ & \\
\hline \multicolumn{5}{|l|}{ Years since graduation } \\
\hline - Less than one & $5.6(3.6$ to 7.6$)$ & \multirow{2}{*}{$0.603^{(\mathrm{b})}$} & 1 [Reference] & \multirow{2}{*}{0.415} \\
\hline - $\quad$ More than one & $4.9(3.0$ to 6.8$)$ & & $0.2(-0.3$ to 0.7$)$ & \\
\hline \multicolumn{5}{|l|}{ Level of training } \\
\hline - $\quad$ House staff & $1.0(0.1$ to 1.9$)$ & \multirow[b]{2}{*}{$<0.0001^{(b)}$} & 1 [Reference] & \multirow[b]{2}{*}{1.432} \\
\hline $\begin{array}{l}\text { - Postgraduate } \\
\text { trainee }\end{array}$ & $10.0(8.6$ to 11.6$)$ & & $-1.8(-2.2$ to -1.5$)$ & \\
\hline
\end{tabular}

(a)To adjust for multiple pair-wise comparisons, $P<0.01$ two-tailed is considered as statistically significant; (b)Analysis by independent $t$ test; (c)Analysis by one way analysis of variance (ANOVA); (d)Using forward stepwise regression, none of the factors were found to be associated significantly with knowledge scores. The $R^{2}$ value (adjusted) for the final model was 0.62 .

\section{Discussion and conclusion}

Though the respondents had a moderate attitude towards biostatistics and moderate number of them felt confident in their current level of ability of understanding biostatistics, they seriously lacked the knowledge needed to interpret research results. Research journal reading habit was seriously lacking and no one had ever taken any research courses. Though bivariate analysis identified institution and level of training as the influencing factors of knowledge scores, multiple regression analysis could not establish the influence of any. 
Our survey was limited in the sense that we did not intend to assess understanding of all biostatistical concepts and research results that was not possible as well. Respondents who did not returned the questionnaire or were absent in the days of the survey, might have scored differently. Also, our study was restricted to sample size of 74 only and respondents from West Bengal only, limiting generalizability to other Indian scenario. Despite these limitations, this study also has several strengths. First, it was the first ever conducted study that captured information on biostatistics in a wide range of respondents. Second, the respondents in our survey, although limited to a single state in India, possessed characteristics similar to others across India. Third, the postgraduate training or house staff programs were similar in composition and duration to the average Indian homeopathic postgraduate and house staff programs, and thus our study appears to be generalizable to HSs and PGTs in India. Internal consistency of the questionnaires might further be improved by rephrasing few question items having inappropriate level of 'non-applicable' scores and relatively low item-rest correlation. Further validation in other Indian samples and more specific statistical (Rasch) analyses will have to confirm whether the sequence of the original questionnaire will require readjustment in Indian scenario.

Similar studies found the mean correct answers of the participants as $41.4-71.5 \%$ [8] and $43.8 \%$ [12] respectively, a figure quite higher than found in our study. Higher scores were associated with prior biostatistics trainings in the earlier studies [8, 12]; however, influence of this variable could not be elicited in our study because no one had undergone such trainings. Influence of academic standings on knowledge score could not be substantiated definitely in our study, that corroborate with our earlier findings, where there were no differences between the knowledge and attitude scores of HSs and PGTs [12]. The study by Polychronopoulou A et al. [8] inferred at a 'surprising' finding from their study that only $11.8 \%$ responders were unable to identify the appropriate use of the chi-square test; but our study reflected poorer figure of only $6.8 \%$. Other responses were similarly dismal. While percentages of correct answers for the knowledge-based questions varied between $10.5-87.4 \%$ in the study by Windish D et al [12] and between $3.2-70.8 \%$ in the study by Polychronopoulou A et al. [8], it showed only $0-9.5 \%$ correct responses in our study. While a positive attitude towards and confidence about biostatistics ranged between $19.9-63 \%$ and $65.3-83.5 \%$ respectively in the study by Polychronopoulou A et al. [8], it was $21.6-85.1 \%$ and $55.4-81.1 \%$ in our study. Another survey [13] demonstrated that only $17.6 \%$ of medical students, internal medicine residents, and internal medicine teaching faculties believed that they had adequate training in biostatistics, $14.6 \%$ felt adequately prepared to conduct a statistical analysis, and just one-quarter of participants reported that they could identify if correct statistical methods had been applied, whereas almost 9 out of 10 believed that they would benefit from further biostatistical training.

The poor knowledge in biostatistics and interpretation of study results among HSs and PGTs in our study likely reflects insufficient training. The poor results were quite obvious, especially in the background of almost non-existent undergraduate homeopathic research [14]. No one of the respondents indicated that they ever received biostatistics or research training at any point in their career. This inadequate preparation demonstrates lack of competence. This finding implies a need to modify the current curriculum format on biostatistics in homeopathy and to include topics that would focus on research design of methods most frequently encountered in homeopathic research. Training programs needs to be interactive, self-directed, and needs to undergo massive and immediate transformation to include more effective biostatistics training in curricula to encourage meaningful research. Access to research resources, like homeopathic and CAM journals needs to be initiated and enhanced at the earliest. Though higher levels of statistical methods are being used in contemporary medical literature and even in homeopathic researches as well, but still, the basic concepts, frequently occurring tests, and interpretation of results are not understood by the study participants. Statistical methods like $t$ test, chi-square test, ANOVA, regression models, receiver operating characteristic (ROC) curves are being extensively used in the current homeopathic clinical researches. Bayesian approach is increasingly being implemented in homeopathic pathogenetic trials and clinical verifications. Most of the 
research papers are reporting ' $P$ values' to highlight the significance of findings. If homeopathic physicians cannot detect appropriately these basic statistical analyses and accurately understand their results, the risk of incorrect interpretation may lead to erroneous and ignorant applications of research in practice. Educators should re-evaluate how this information is taught and reinforced in order to adequately prepare trainees for lifelong learning, and further research should examine the effectiveness of specific educational interventions.

\section{Acknowledgment}

The authors would like to thank Dr. Donna M Windish for permitting us to use the questionnaire in our study and Dr. Chapal Kumar Bhattacharyya, Principal in-Charge, MHMCH; Dr. Akhilesh Khan, Principal inCharge, DNDHMCH; Dr. Nikhil Saha, Principal in-Charge, MBHMCH; and Dr. Mahadeb De, Principal, $\mathrm{CHMCH}$ for allowing us to carry out the project successfully in their institutions. Authors will also remain grateful to the respondents for their participation.

\section{References}

[1] Griffin MF, Hindocha S. Publication practices of medical students at British medical schools: Experience, attitudes and barriers to publish. Med Teach. 2011;33:e1-e8. doi: 10.3109/0142159X.2011.530320. PMID: 21182368. Available at: http://www.ncbi.nlm.nih.gov/pubmed/21182368

[2] Askew DA, Clavarino AM, Glasziou PP, Del Mar CB. General practice research: attitudes and involvement of Queensland general practitioners. MJA. 2002;177:74-77. PMID: 12098342. Available at: http://www.ncbi.nlm.nih.gov/pubmed/12098342

[3] Vujaklija A, Hren D, Sambunjak D, Vodopivec I, Ivanis A, Marusi A, Marusi M. Can teaching research methodology influence students' attitude toward science? Cohort study and nonrandomized trial in a single medical school. J Investig Med. 2010;58(2):282-6. PMID: 20130460. doi: 10.231/JIM.0b013e3181cb42d9. Available at: http://www.ncbi.nlm.nih.gov/pubmed/20130460

[4] Siemens DR, Punnen S, Wong J, Kanji N. A survey on the attitudes towards research in medical school. BMC Med Educ. 2010;10:4. PMID: 20096112. PMCID: PMC2823602. doi: 10.1186/1472-6920-10-4. Available at: http://www.biomedcentral.com/1472-6920/10/4

[5] Khan H, Khan S, Iqbal A. Knowledge, attitudes and practices around health research: the perspective of physicians-in-training in Pakistan. BMC Med Educ. 2009;9:46. PMCID: PMC2719622. PMID: 19615071. doi: 10.1186/1472-6920-9-46. Available at: http://www.biomedcentral.com/1472-6920/9/46

[6] Goldhamer MEJ, Cohen AP, Bates DW, Cook EF, Davis RB, Singer DE, Simon SR. Protecting an endangered species: training physicians to conduct clinical research. Acad Med. 2009;84:439-445. PMID: 19318774. doi: 10.1097/ACM.0b013e31819a7cb1. Available at: http://www.ncbi.nlm.nih.gov/pubmed/19318774

[7] Dickler HB, Korn D, Gabbe SG. Promoting translational and clinical science: The critical role of medical schools and teaching hospitals. PLoS Med. 2006;3:e378. doi:10.1371/journal.pmed.0030378. Available at: http://www.ncbi.nlm.nih.gov/pmc/articles/PMC1570187

[8] Polychronopoulou A, Eliades T, Taoufik K, Papadopoulos MA, Athanasiou AE. Knowledge of European orthodontic postgraduate students on biostatistics. European J Orthodont. 2011;33:434-440. Available at: http://ejo.oxfordjournals.org/content/33/4/434.full.pdf+html

[9] Koley M, Saha S, Arya JS, Choubey G, Ghosh A, Saha S, Ghosh S, Ganguly S. Knowledge and attitude towards homeopathic research: the perspective of new graduates and postgraduate trainees - an Indian 
scenario. Focus Altern Complement Ther. 2014;19(3):119-125. Available at: http://onlinelibrary.wiley.com/doi/10.1111/fct.12115/abstract

[10] Koley M, Saha S, Arya JS, Choubey G, Ghosh S, Purkait R, et al. A study on drug utilization and prescription habits of physicians in a government homeopathic hospital in West Bengal, India. J Integr Med. 2013;11(5):305-313. doi: 10.3736/jintegrmed2013048. Available at: http://www.ncbi.nlm.nih.gov/pubmed/24063777

[11] Saha S, Koley M, Hossain SI, Mundle M, Ghosh S, Nag G, Datta AK, Rath P. Individualized homeopathy versus placebo in essential hypertension: a double-blind randomized controlled trial. Indian $\mathrm{J}$ Res Homoeopathy. 2013;7(2):62-71. Available at: http://www.ijrh.org/text.asp?2013/7/2/62/116629

[12] Windish DM, Huot SJ, Green ML. Medicine residents' understanding of the biostatistics and results in the medical literature. JAMA 2007;298(9):1010-1022. Available at: http://www.ncbi.nlm.nih.gov/pubmed/17785646

[13] West CP, Ficalora RD. Clinicians attitudes towards biostatistics. Mayo Clinic Proceedings 2007;82:939943. Available at: http://www.mayoclinicproceedings.org/article/S0025-6196(11)61335-9/abstract

[14] Mundle M, Saha S, Koley M, Arya JS, Choubey G, Saha S, Ghosh A, Ganguly S, Ghosh S. A survey exploring research perception of homeopathic undergraduate students in West Bengal, India. Int J High Dilution Res [online]. 2014 [cited 2014 Sept. 15];13(46):28-44. Available from: http://www.feg.unesp.br/ ojs/index.php/ijhdr/article/view/688/691

\section{(c) BY-NC-ND Licensed to GIRI}

Support: authors declare that this study received no funding

Conflict of interest: authors declare there is no conflict of interest

Received: February 17, 2014; Revised: August 29th 2014 ; Published: September 30 2014.

Correspondence author: Subhranil Saha, drsubhranilsaha@hotmail.com

How to cite this article: Saha S, Koley M, Mondal R, Kundu M, Ghosh A, Ghosh S, Saha S, Ganguly S. Understanding of biostatistics among the homeopathic fresh graduates and post-graduate trainees in West Bengal, India. Int $\mathrm{J}$ High Dilution Res [online]. 2014 [cited YYYY Month dd]; 13(48): 172-181. Available from: http:// www.feg.unesp.br/ ojs/index.php/ijhdr/article/view/705/730 